\title{
Current recommendations regarding vaccination of patients with autoimmune inflammatory rheumatic diseases
}

\author{
Ramona Stefania Popescu ${ }^{1,2}$, Oana Sandulescu ${ }^{1,2}$, Anca Streinu-Cercel ${ }^{1,2}$, \\ Andra Balanescu ${ }^{1,3}$, Ruxandra Ionescu ${ }^{1,3}$, Adrian Streinu-Cerce $\left.\right|^{1,2}$ \\ 1"Carol Davila" University of Medicine and Pharmacy, Bucharest, Romania \\ 2"Prof. Dr. Matei Bals" National Institute for Infectious Diseases, Bucharest, Romania \\ IInternal Medicine and Rheumatology Clinic, "Sf. Maria" Hospital, Bucharest, Romania
}

\begin{abstract}
Background. Patients suffering from autoimmune inflammatory rheumatic diseases (AlIRD) are exposed to a higher risk of infections due to both their background and the immunosuppressant and immunomodulatory medications. This brings us to the question of what we can do to ensure the protection of our patients. And one of the answers should be vaccination.

Methods. We performed a literature search in electronic database (PubMed) using keywords related to vaccination and rheumatic diseases. Also, relevant information concerning vaccination recommendations were collected form a website search of specific organizations dealing with management of autoimmune rheumatic disease in various countries.

Results. Patients with AIIRD are at increased risk of infections and even if some of them could be prevented in part by vaccines, the rates of vaccination in this category of patients remains low. The 2015 American College of Rheumatology (ACR) guideline for the treatment of rheumatoid arthritis recommends the administration of influenza, pneumococcal, hepatitis B, human papilloma and shingles vaccines in patients requiring diseasemodifying antirheumatic drugs (DMARDs) or biologics, the first three being strongly recommended in patients with rheumatoid arthritis. The guideline does not recommend the administration of life attenuated vaccines, such as shingles vaccine, in patients under biologics. These are consistent with the recommendations from the Centers for Disease Control and Prevention (CDC) for vaccination of immunocompromised patients. In cases where live attenuated vaccines need to be used, the immunosuppressive therapy should be delayed by at least 4 weeks following vaccination.

Conclusions. Despite important differences between different countries, there is a general consensus on the importance of immunizing AIIRD patients through vaccination. The most widely recommended vaccination regimens refer to influenza and pneumococcal vaccines, but other specific vaccines such as hepatitis $B$, human papilloma virus, herpes zoster, meningococcal, and Haemophilus influenzae type b should also be considered.
\end{abstract}

Keywords: vaccination, rheumatic disorders, immunodeficiency

\section{BACKGROUND}

Patients suffering from autoimmune inflammatory rheumatic diseases (AIIRD) are exposed to a higher risk of infections due to both their background and the immunosuppressant and immunomodulatory medications. This brings us to the question of what we can do to ensure the protection of our patients. And one of the answers should be vaccination. However, practitioners still retain some concerns about safety, the right timing, and the efficacy of vaccines in this particular category of patients.

\section{METHODS}

We performed a literature search in electronic database (PubMed) using the keywords: "vaccination", "rheumatic disease", "safety biologic therapy", "influenza immunization", pneumococcal immunization", "meningococcal immunization", "hepatitis B immunization", "herpes zoster immunization" and "human papilloma virus immunization". Also, relevant information concerning vaccination recommendations were collected form a website search of specific organizations dealing with management of autoimmune rheumatic disease in various countries. 


\section{RESULTS}

In Europe, around $2 \%$ of the adult population suffers from an autoimmune inflammatory rheumatic disease (1). Patients with AIIRD are at increased risk of infections (2), of which more than $90 \%$ are respiratory, urogenital or cutaneous/soft tissue infections (2-4). Even if some of them could be prevented in part by vaccines, the rates of vaccination in this category of patients remains low (5-8). Studies show that the main reason for not vaccinating is the lack of a recommendation from a healthcare worker (7, 9-11) which is probably due to a degree of reluctance regarding the efficacy and the common misconception regarding the potential role of vaccines as triggers for autoimmune disease flares.

The 2015 American College of Rheumatology (ACR) guideline for the treatment of rheumatoid arthritis (RA) (12) recommends the administration of influenza, pneumococcal, hepatitis B, human papilloma and shingles vaccines in patients requiring disease-modifying antirheumatic drugs (DMARDs) or biologics, the first three being strongly recommended in patients with rheumatoid arthritis who are currently receiving biologics. The guideline does not recommend the administration of life attenuated vaccines, such as shingles vaccine, in patients under biologics. These are consistent with the recommendations from the Centers for Disease Control and Prevention (CDC) for vaccination of immunocompromised patients (13). In cases where live attenuated vaccines need to be used, the immunosuppressive therapy should be delayed by at least 4 weeks following vaccination $(1,14,15)$.

Notably, the table only summarizes the data identified specifically for patients with autoimmune rheumatic diseases, and therefore vaccinations already included in each national vaccination regimen are not encompassed in the table, and neither are general recommendations for immunocompromised patients.

TABLE 1. National guidelines regarding the vaccination recommendations for patients with autoimmune rheumatic diseases

\begin{tabular}{|c|c|c|c|c|c|c|c|c|}
\hline & Influenza & Pneumococcal & HBV & HAV & HPV & $\mathrm{HZ}$ & Meningococcal & $\mathrm{Hib}$ \\
\hline Brazil (16) & Y (PPSV23) & $Y$ & $\mathrm{Y}$ & $\mathrm{Y}$ & $\mathrm{Y}^{*}$ & $Y$ & $\begin{array}{c}\text { Y (if asplenic/ } \\
\text { complement } \\
\text { deficient/during } \\
\text { outbreaks) }\end{array}$ & $\begin{array}{c}Y \\
\text { (if } \\
\text { asplenic) }\end{array}$ \\
\hline $\begin{array}{l}\text { USA (ACR) } \\
(17)\end{array}$ & $\begin{array}{c}\text { Y } \\
\text { (PCV13 or } \\
\text { PPSV23 in } \\
\text { elderly patients, } \\
\text { asthmatics, or } \\
\text { smokers) }\end{array}$ & $Y$ & $\begin{array}{l}Y \text { (if risk } \\
\text { factors are } \\
\text { present) }\end{array}$ & & $\mathrm{Y}^{*}$ & Y & & \\
\hline $\begin{array}{l}\text { Europe } \\
\text { (EULAR) } \\
(18) \\
\end{array}$ & $\begin{array}{c}Y \\
\text { (PPSV23) }\end{array}$ & $Y$ & $\begin{array}{l}Y \text { (if risk } \\
\text { factors are } \\
\text { present) }\end{array}$ & $\begin{array}{c}Y \text { (if risk } \\
\text { factors are } \\
\text { present) }\end{array}$ & $\mathrm{Y}^{*}$ & $Y$ & Y, menC (if asplenic) & $\begin{array}{c}\mathrm{Y} \\
\text { (if } \\
\text { asplenic) } \\
\end{array}$ \\
\hline Italy (19) & $\begin{array}{c}Y \\
\text { (PPSV23) }\end{array}$ & Y & $\begin{array}{l}\mathrm{Y} \text { (psoriatis } \\
\text { arthritis)(20) }\end{array}$ & & & & & \\
\hline Spain (21) & $\begin{array}{c}\mathrm{Y} \\
\text { (if biologic } \\
\text { al therapy } \\
\text { needed) }\end{array}$ & $\begin{array}{c}\mathrm{Y} \\
\text { (if biologic al } \\
\text { therapy needed) }\end{array}$ & $\begin{array}{c}\mathrm{Y} \\
\text { (if biologic } \\
\text { al therapy } \\
\text { needed) }\end{array}$ & & & & & \\
\hline $\begin{array}{l}\text { Germany } \\
(22)\end{array}$ & Y & $\begin{array}{c}\text { Y (PPSV23 } \\
\text { for all adults, } \\
\text { PCV }>50 \\
\text { years old) }\end{array}$ & y & y & y & $\begin{array}{c}\text { Y, VZV } \\
\text { (if } \\
\text { immunosuppr } \\
\text { essed) }\end{array}$ & $\begin{array}{c}\text { Y, 1- or 4-valent } \\
\text { (if asplenic, } \\
\text { complement } \\
\text { deficient SLE, } \\
\text { hypogammaglobuli } \\
\text { nemia, other } \\
\text { immunedeppre- } \\
\text { ssion) }\end{array}$ & $\begin{array}{c}\mathrm{Y} \\
\text { (if asplen } \\
\text { ic) }\end{array}$ \\
\hline
\end{tabular}


Furthermore, as soon as a patient is diagnosed with AIIRD, a complete assessment of the vaccination status should be performed, and recommended vaccinations should be administered promptly (1).

The European League Against Rheumatism (EULAR) recommends vaccination during stable disease, and ideally prior to starting DMARDs therapy (23). However, considering that studies are generally performed in patients with stable, quiescent disease (24), it is difficult to assess the right moment for vaccinating in relation to disease activity and to the receipt of treatment potentially affecting vaccination effectiveness.

Despite the fact that for many years there have been debates regarding the possible causal relationship between vaccination and autoimmune diseases (25), there is no reliable evidence to sustain this, with the exception of certain autoimmune reactions described with the use of specific vaccines [for example, Guillain Barré syndrome (GBS) after 1976 swine influenza $\mathrm{A}(\mathrm{H} 1 \mathrm{~N} 1)$ subtype $\mathrm{A} / \mathrm{NJ} / 76$ vaccination or immune thrombocytopenic purpura after mumps/measles/rubella (MMR) vaccine] (26). In addition, clinical surveillance indicates that immunization of AIIRD patients does not cause an increase of clinical or laboratory parameters of disease activity $(27,28)$.

Even if the immunogenicity of vaccines could be reduced by the immunosuppressive drugs, it still remains adequate (29). The only real concern remains the use of abatacept, which has been shown to significantly reduce the antibody response to influenza, pneumococcal and tetanus toxoid vaccination (30), and rituximab after which the humoral immune responses to influenza and pneumococcal vaccination are nearly absent (31). The same recommendation are made for tocilizumab (32). For this reason, it is recommended that vaccination precede rituximab administration or be postponed for at least 6 months after rituximab infusion (31). However, if a vaccine, such as influenza, needs to be administered within a certain time interval, vaccination can be performed, although lower vaccine effectiveness is expected (15).

Summarizing all the above data some key recommendations can be formulated:

1. Vaccination does not appear to cause autoimmune inflammatory rheumatic diseases or exacerbate them, so we may say that the benefits of vaccination outweigh the risks of acquiring infection.

2. For patients with autoimmune inflammatory rheumatic disease that are not under immunosup- pressive treatment there are no exact contraindications for vaccination regardless of the type of vaccine used.

3. Assess and document the vaccination status of the patients as soon as an AIIRD is diagnosed. Administer the recommended vaccinations immediately if possible. Preferably, vaccination should be done before the start of immunosuppressive therapy. In the case of live attenuated vaccines, the immunosuppressive treatment should be started at least four weeks after the vaccination.

4. In case of already treated AIIRD patients, it would be ideal to vaccinate them at the lowest point of the immunosuppressive therapy.

5. In patients with AIIRD under immunosuppressive treatment, inactivated vaccines are generally considered safe, however they may result in reduced immunogenicity.

6. Administering live vaccines to immunosuppressed patients presents the risk of replication of the attenuated microorganism and consequent invasive infection, therefore these should be used with caution when the patients are undergoing immunosuppressive therapy.

7. Patients with AIIRD should receive the same recommendations for basic vaccinations as the general population, as well as additional recommendations for specific immunizations.

8. For AIIRD patients the following minimum set of specific vaccinations are widely recommended: annual influenza immunization, pneumococcal immunization. Despite a degree of debate regarding the type of vaccine that should be used, the 13-valent pneumococcal conjugate vaccine appears to have an advantage over the 23-valent polysaccharide vaccine. Also, vaccination against hepatitis B should be encouraged in all AIIRD patients despite the fact that many countries only recommend this vaccine for patients exhibiting at-risk behaviors. For female patients aged 11-26 years with systemic lupus erythematosus or some other AIIRD, vaccination against human papillomavirus should be done, the same as in the general population. Another recommendation for AIIRD patients aged $>50$ years is herpes zoster vaccination, but unfortunately this type of vaccine is currently unavailable in Romania.

9. When possible, conjugate vaccines should be used instead of polysaccharide ones because they induce affinity antibody responses that are higher, immune responses that are longer lasting and also memory responses. 
10. It is preferable to administer vaccination during stable disease.

\section{CONCLUSIONS}

Despite important differences between different countries, there is a general consensus on the importance of immunizing AIIRD patients through vaccination. The most widely recommended vaccination regimens refer to influenza and pneumococcal vac- cines, but other specific vaccines such as hepatitis B, human papilloma virus, herpes zoster, meningococcal, and Haemophilus influenzae type b should also be considered.

\section{Acknowledgement:}

This work was supported by the Sectoral Operational Programme Increasing of Economic Competitiveness (POS CCE) (grant number: 1871/49153).

\section{Conflict of interest: none declared}

\section{REFERENCES}

1. Buhler S., Eperon G., Ribi C., Kyburz D., van Gompel F., Visser L.G., et al. Vaccination recommendations for adult patients with autoimmune inflammatory rheumatic diseases. Swiss Med Wkly. 2015; 145:w14159.

2. Germano V., Cattaruzza M.S., Osborn J., Tarantino A., Di Rosa R., Salemi S., et al. Infection risk in rheumatoid arthritis and spondyloarthropathy patients under treatment with DMARDs, corticosteroids and TNF-alpha antagonists. J Transl Med. 2014; 12:77.

3. Salliot C., Gossec L., Ruyssen-Witrand A., Luc M., Duclos M., Guignard S., et al. Infections during tumour necrosis factoralpha blocker therapy for rheumatic diseases in daily practice: a systematic retrospective study of 709 patients. Rheumatology (Oxford). 2007; 46(2):327-34.

4. Listing J., Strangfeld A., Kary S., Rau R., von Hinueber U., Stoyanova-Scholz M., et al. Infections in patients with rheumatoid arthritis treated with biologic agents. Arthritis Rheum. 2005; 52(11):3403-12.

5. Reich J., Wasan S., Farraye F.A. Vaccinating Patients With Inflammatory Bowel Disease. Gastroenterol Hepatol (N Y). 2016; 12(9):540-6

6. Hmamouchi I., Winthrop K., Launay O., Dougados M. Low rate of influenza and pneumococcal vaccine coverage in rheumatoid arthritis: data from the international COMORA cohort. Vaccine. 2015; 33(12):1446-52.

7. Sandler D.S., Ruderman E.M., Brown T., Lee J.Y., Mixon A., Liss D.T., et al. Understanding vaccination rates and attitudes among patients with rheumatoid arthritis. Am J Manag Care. 2016; 22(3):161-7.

8. Nguyen M., Lindegaard H., Hendricks O., Friis-Moller N. Factors associated with influenza and pneumococcal vaccine uptake among rheumatoid arthritis patients in Denmark invited to participate in a pneumococcal vaccine trial (Immunovax_RA). Scand J Rheumatol. 2017:1-8.

9. Assala M., Groh M., Blanche P., Vinter C., Cohen P., Le Guern V., et al. Pneumococcal and influenza vaccination rates in patients treated with corticosteroids and/or immunosuppressive therapies for systemic autoimmune diseases: A cross-sectional study. Joint Bone Spine. 2016.

10. Hua C., Morel J., Ardouin E., Ricard E., Foret J., Mathieu S., et al. Reasons for non-vaccination in French rheumatoid arthritis and spondyloarthritis patients. Rheumatology (Oxford). 2015; 54(4):748-50

11. Lawson E.F., Trupin L., Yelin E.H., Yazdany J. Reasons for failure to receive pneumococcal and influenza vaccinations among immunosuppressed patients with systemic lupus erythematosus. Semin Arthritis Rheum. 2015; 44(6):666-71.

12. Singh J.A., Saag K.G., Bridges S.L., Jr., AkI E.A., Bannuru R.R., Sullivan M.C., et al. 2015 American College of Rheumatology Guideline for the Treatment of Rheumatoid Arthritis. Arthritis Care Res (Hoboken). 2016; 68(1):1-25.

13. Kim D.K., Riley L.E., Harriman K.H., Hunter P., Bridges C.B., Advisory Committee on Immunization P. Recommended
Immunization Schedule for Adults Aged 19 Years or Older, United States, 2017. Ann Intern Med. 2017; 166(3):209-19.

14. Cordeiro I., Duarte A.C., Ferreira J.F., Goncalves M.J., Meirinhos T., Rocha T.M., et al. Recommendations for Vaccination in Adult Patients with Systemic Inflammatory Rheumatic Diseases from the Portuguese Society of Rheumatology. Acta Reumatol Port. 2016; 41(2):112-30.

15. Tanriover M.D., Akar S., Turkcapar N., Karadag O., Ertenli I., Kiraz S. Vaccination recommendations for adult patients with rheumatic diseases. Eur J Rheumatol. 2016; 3(1):29-35.

16. Brenol C.V., da Mota L.M., Cruz B.A., Pileggi G.S., Pereira I.A., Rezende L.S., et al. 2012 Brazilian Society of Rheumatology Consensus on vaccination of patients with rheumatoid arthritis. Rev Bras Reumatol. 2013; 53(1):4-23.

17. Singh J.A., Saag K.G., Bridges S.L., Jr., Akl E.A., Bannuru R.R., Sullivan M.C., et al. 2015 American College of Rheumatology Guideline for the Treatment of Rheumatoid Arthritis. Arthritis Rheumatol. 2016; 68(1):1-26.

18. van Assen S., Agmon-Levin N., Elkayam O., Cervera R., Doran M.F., Dougados M., et al. EULAR recommendations for vaccination in adult patients with autoimmune inflammatory rheumatic diseases. Ann Rheum Dis. 2011; 70(3):414-22. Società Italiana di Reumatologia per i pazienti affetti da malattie reumatiche infiammatorie croniche in trattamento con farmaci immunosoppressori e biologici. 2009 [15/03/2017]. Available from: http://www.reumatologia.it/obj/file/allegato.pdf.

20. Salvarani C., Pipitone N., Marchesoni A., Cantini F., Cauli A., Lubrano E., et al. Recommendations for the use of biologic therapy in the treatment of psoriatic arthritis: update from the Italian Society for Rheumatology. Clin Exp Rheumatol. 2011; 29(3 Suppl 66):S28-41.

21. Gomez Reino J., Loza E., Andreu J.L., Balsa A., Batlle E., Canete J.D., et al. [Consensus statement of the Spanish Society of Rheumatology on risk management of biologic therapy in rheumatic patients]. Reumatol Clin. 2011;7(5):284-98.

22. Warnatz K., Goldacker S., Gause A.M., die Kommission Pharmakotherapie der D. [Vaccination recommendations of the Commission for Pharmacotherapy of the German Society of Rheumatology]. Z Rheumatol. 2013; 72(7):687-9.

23. Costello R., Winthrop K.L., Pye S.R., Brown B., Dixon W.G. Influenza and Pneumococcal Vaccination Uptake in Patients with Rheumatoid Arthritis Treated with Immunosuppressive Therapy in the UK: A Retrospective Cohort Study Using Data from the Clinical

24. van Assen S., Elkayam O., Agmon-Levin N., Cervera R., Doran M.F., Dougados M., et al. Vaccination in adult patients with autoimmune inflammatory rheumatic diseases: a systematic literature review for the European League Against Rheumatism evidencebased recommendations for vaccination in adult patients with auto-immune inflammatory rheumatic diseases. Autoimmun Rev. 2011; 10(6):341-52.
19. Reumatologia SId. Nuova influenza A(H1N1) Consigli della Practice Research Datalink. PLoS One. 2016; 11(4):e0153848. 
25. Salemi S., D‘Amelio R. Could autoimmunity be induced by vaccination? Int Rev Immunol. 2010; 29(3):247-69.

26. Esposito S., Prada E., Mastrolia M.V., Tarantino G., Codeca C., Rigante D. Autoimmune/inflammatory syndrome induced by adjuvants (ASIA): clues and pitfalls in the pediatric background. Immunol Res. 2014; 60(2-3):366-75.

27. Rahier J.F., Moutschen M., Van Gompel A., Van Ranst M., Louis E., Segaert S., et al. Vaccinations in patients with immunemediated inflammatory diseases. Rheumatology (Oxford). 2010;49(10):1815-27.

28. Bengtsson C., Kapetanovic M.C., Kallberg H., Sverdrup B., Nordmark B., Klareskog L., et al. Common vaccinations among adults do not increase the risk of developing rheumatoid arthritis: results from the Swedish EIRA study. Ann Rheum Dis. 2010; 69(10):1831-3

29. Pasoto S.G., Ribeiro A.C., Bonfa E. Update on infections and vaccinations in systemic lupus erythematosus and Sjogren's syndrome. Curr Opin Rheumatol. 2014; 26(5):528-37.
30. Tay L., Leon F., Vratsanos G., Raymond R., Corbo M. Vaccination response to tetanus toxoid and 23-valent pneumococcal vaccines following administration of a single dose of abatacept: a randomized, open-label, parallel group study in healthy subjects. Arthritis Res Ther. 2007; 9(2):R38.

31. van Assen S., Holvast A., Benne C.A., Posthumus M.D., van Leeuwen M.A., Voskuyl A.E., et al. Humoral responses after influenza vaccination are severely reduced in patients with rheumatoid arthritis treated with rituximab. Arthritis Rheum. 2010; 62(1):75-81.

32. Pham T., Claudepierre P., Constantin A., de Bandt M., Fautrel B., Gossec L., et al. Tocilizumab: therapy and safety management. Joint Bone Spine. 2010; 77 Suppl 1:S3-100. 